\title{
PARADIGMA INTERPRETATIVO NOS ESTUDOS DE CONSUMO: RETROSPECTIVA, REFLEXÕES E UMA AGENDA DE PESQUISAS PARA 0 BRASIL
}

\author{
Angela da Rocha \\ Coppead/UFRJ \\ Everardo Rocha \\ PUC-Rio e Coppead/UFRJ
}

A adoção de uma perspectiva interpretativa nos estudos de marketing é um fenômeno recente, tanto no Brasil quanto em outros países. No entanto, trata-se de um movimento que já conquistou fóruns respeitáveis na disciplina de Marketing, sendo acolhido nos principais congressos internacionais da área e dispondo de espaços acadêmicos próprios. Nesta edição da "RAE-Clássicos", buscamos colocar em discussão o uso do paradigma interpretativo nos estudos de consumo, delineando suas origens, apontando sua inserção e discutindo dificuldades e potencialidades de sua difusão no marketing brasileiro.

\section{CULTURA E NEGÓCIOS: UM LONGO CAMINHO}

A primeira área de negócios a se preocupar com as questões referentes a diferenças culturais foi a de Gestão Internacional, particularmente a de Marketing Internacional. Ao lidar com consumidores de diferentes mercados, os teóricos e praticantes do marketing se deram conta da existência de diferenças no consumo que pareciam associadas a diferenças nos valores sociais e nos costumes de diferentes povos. Por isso mesmo, a presença de capítulos ou seções em livros didáticos dedicados à importância do entendimento da cultura nos negócios internacionais e no marketing internacional é antiga, podendo ser encontrada há pelo menos 50 anos. No entanto, essa presença é, por décadas, apenas lateral, não obtendo centralidade no pensamento acadêmico voltado para a Gestão Internacional.

Exceção a isso é o trabalho do antropólogo Edward T. Hall $(1966,1983)$, que se dedicou a estudar exatamente como as diferenças culturais impactavam os negócios in- ternacionais, em particular a negociação internacional. Ele chamou a atenção para aspectos como tempo, espaço e linguagem, como fundamentais ao entendimento do processo de fazer negócios em outros países. Criticado por muitos antropólogos mais conservadores pelo uso prático da Antropologia nos negócios, Hall foi uma estrela solitária que não deixou seguidores.

Importante contribuição para o entendimento da cultura nas organizações de negócios foi dada por Geert Hofstede, embora esse autor utilize uma abordagem positivista ao entendimento das diferenças culturais. Lastreado no conhecimento sociológico, ele desenvolveu questionários estruturados para medir diferenças culturais entre organizações em diversos países, classificando os países em clusters culturais e proporcionando uma "medida" dessas diferenças. O trabalho de Hofstede $(1984,1991)$ custou a adquirir visibilidade no meio acadêmico, mas sua influência na produção acadêmica internacional de Administração é inconteste. Apesar de outros arcabouços teóricos para classificação de clusters culturais terem sido desenvolvidos para uso dos pesquisadores, o trabalho original de Hofstede, ampliado e modificado por pesquisas posteriores, é possivelmente o principal referencial para estudos interculturais na área de Administração até hoje.

Também nos manuais de marketing, nos capítulos devotados às teorias sobre o comportamento do consumidor, alguns autores dedicaram capítulos ou seções às questões culturais (por exemplo, Stanton, 1970; Boyd, 1972), em geral para chamar a atenção para a existência de subculturas, grupos étnicos ou lingüísticos no mercado dos Estados Unidos. Mesmo as obras dedicadas ao estudo do comportamento do consumidor, em sua maior parte apenas tangenciavam a questão do lugar da cultura no 
entendimento do comportamento do consumidor. Mesmo assim, a cultura se inseria nos estudos de marketing como algo exótico, que explicava as diferenças dos "outros", mas que nada tinha a dizer sobre o modo como se comportavam os consumidores "normais".

Sidney Levy, da Northwestern University, foi um dos primeiros acadêmicos a contribuir com uma visão interpretativa dos estudos de marketing, o que se deveu, em grande parte, ao seu background em Sociologia, obtido na Universidade de Chicago. Posteriormente, Levy uniu-se a uma equipe multidisciplinar na Social Research, Inc., empresa dedicada a estudos de consumo, que reunia sociólogos, antropólogos e psicólogos de renome, entre os quais W. Lloyd Warner, que teve influência dominante nos estudos sobre classes sociais em marketing nas décadas de 1950 a 1970. A Social Research, segundo relato do próprio Levy (1995, p. x), "utilizava um amálgama aplicado de teorias e métodos das ciências do comportamento", incluindo entrevistas em profundidade, métodos de observação e técnicas projetivas, "para clarificar questões relativas a estratificação social, papéis sociais, mudança cultural e simbolismo no quotidiano da comunidade". Em artigo publicado em 1981 no Journal of Marketing, Levy advogou o uso de enfoque interpretativo nos estudos de consumo em marketing. Referindo-se à forma como os pesquisadores de marketing utilizavam as informações colhidas de entrevistas pessoais e as citavam pelo seu valor de face, ele observou:

Esta forma de lidar com os dados freqüentemente parece árida e frustrante, por não ser suficientemente penetrante, não dizer o suficiente sobre o significado do produto em relação à vida dos usuários e sobre sua posição em relação a outros produtos. O enfoque sugerido é evitar aceitar respostas como se fossem observações científicas a serem tabuladas como medidas. Ao contrário, a suposição é de que os produtos são usados de forma simbólica, e que contar algo sobre seu uso é uma forma de simbolizar a vida e a natureza da família, o que requer uma teoria de interpretação que determine como os dados podem ser relacionados e compreendidos. (LEVY, 1981, p. 50-51).

No entanto, a aceitação dos estudos de consumo de natureza interpretativa não foi fácil (Levy, 1995). Sherry (1995) salientou ter encontrado, nos Estados Unidos, maior resistência no meio acadêmico ao uso da Antropologia e de seus métodos para explicar o comportamento dos consumidores do que entre os praticantes do marketing, que intuitivamente percebiam melhor sua utilidade.
No decorrer das últimas duas décadas, porém, uma verdadeira e silenciosa revolução no entendimento do comportamento do consumidor e dos processos de consumo está em andamento. Tal revolução consiste em que a cultura passou a ocupar um espaço central no pensamento de marketing, não mais para explicar diferenças de práticas de marketing de determinados povos ou grupos vistos como "exóticos", mas como forma de entender a essência do processo de consumo.

Sob essa perspectiva, todo ato de consumo é visto como impregnado de significado simbólico, sendo o lócus em que se reafirmam, entre outras questões, identidade, pertencimento, hierarquia, status e poder. Os consumidores utilizam bens e serviços para dizer alguma coisa de si mesmos (Douglas e Isherwood, 1979), para reafirmar suas identidades, para definir sua posição no espaço social, para distinguir-se e hierarquizar, para declarar seu pertencimento a um ou a outro grupo, para falar de gênero e etnia, para celebrar ou superar passagens, para afirmar ou negar suas relações com outros, para classificar, ou para atribuir quaisquer outros significados. Tais significados se sobrepõem à simples ordem econômica, material e funcional do consumo.

Selecionamos, para esta edição da "RAE-Clássicos", dois trabalhos que tiveram importante papel em estimular o desenvolvimento de estudos de consumo de orientação interpretativa na disciplina de Marketing: os de Rook (1985) e McCracken (1986), ambos publicados no Journal of Consumer Research, que, desde então, tem sido o veículo principal para a divulgação de estudos de consumo de cunho antropológico.

O trabalho de Rook (1985), um seguidor de Levy, originou-se de sua tese de doutorado, fornecendo indícios do início do reconhecimento dos estudos de consumo interpretativos pela Academia norte-americana, ao ser premiado pela Association for Consumer Research daquele país. Este estudo tem caráter interdisciplinar, utilizando referências e métodos da Antropologia, da Psicologia e da Psicanálise, mas com forte influência da primeira disciplina. Em seu artigo, Rook observou que os rituais urbanos de consumo haviam sido esquecidos até mesmo pelos antropólogos, mas que desempenhavam papel central no processo de consumo. O comportamento ritualístico, diz ele, está "associado a extensas trocas de bens e serviços, freqüentemente consumidos em ocasiões dramáticas, cerimoniais ou, até mesmo, solenes" (Rook, 1985, p. 251). Diversos estudos de caráter interpretativo, voltados para rituais de consumo, seguiram-se ao de Rook, salientando-se os de Gainer e Fischer (1991), Schouten (1991) e Gainer (1995). 
O texto de McCracken (1986), um antropólogo que se especializou em estudos de consumo, fornece um referencial teórico para orientar os estudos sobre comportamento do consumidor sob a perspectiva antropológica. Essencialmente, McCracken sugere que a leitura do comportamento de consumo deve se dar por meio da busca de significados que são criados e transferidos. O movimento dos significados do mundo culturalmente constituído para os bens de consumo se produz em grande parte pela ação da propaganda e do sistema de moda, mas não se detém aí, sendo transferido para o consumidor, que se apropria desses significados para definir questões como identidade, posição no espaço social, pertencimento a grupos, status, entre muitas outras.

Nesse e em outros trabalhos (McCracken, 2003), o autor investiga sugestivas questões sobre as complexas relações entre cultura e consumo. Uma de suas preocupações é situar historicamente o surgimento do consumo moderno, mostrando como este fenômeno é fruto de um grande processo de transformação nos valores da chamada cultura ocidental. Para McCracken, o surgimento do consumo acontece na Inglaterra do século XVI, no período elizabetano. Depois disso, dois outros momentos são registrados como marcantes: um deles é o século XVII, com a expansão do consumo para outras esferas da vida social, e o outro o século XIX, com a consolidação do fenômeno em bases permanentes. McCracken aproxima o consumo na era elizabetana à idéia de que Elizabeth I utilizou o gasto como instrumento político. A vida cotidiana em sua corte tinha caráter ostentatório e conspícuo que servia como forma de expressão para os significados do poder e da majestade, imprimindo forte competição social entre os nobres para se destacarem uns dos outros por meio do consumo. A importância desse estudo é mostrar que a questão do consumo está menos relacionada com perspectivas absolutas da esfera biológica das "necessidades" ou da esfera psicológica dos "desejos" e mais com a relatividade dos sistemas culturais.

Outro tema interessante desenvolvido por McCracken (2003) trata do processo de substituição do sistema da pátina pelo sistema da moda como expressão de poder e prestígio. A pátina é uma propriedade da cultura material que revela as marcas do tempo nos objetos. Isso pode traduzir uma mensagem consistente: a idéia de que esses objetos pertencem à mesma família há gerações, e o status de tradição e nobreza daí advindo. A pátina é uma espécie de assinatura, autenticando posição elevada da família na sociedade. O desenvolvimento do consumo no século XVIII sustenta o sistema da moda, que, em certo sentido, vai se opor ao da pátina, e o status começa a transferir seus significados para um sistema baseado na novidade. Os objetos da cultura material, que transmitiam mensagens de prestígio pela antiguidade do sistema da pátina, começam a transmitir esses significados por meio do novo sistema da moda. Uma relação fundamental para a consolidação do consumo se inaugura, vinculando novidade a status.

Outra discussão instigante (McCracken, 2003) refere-se ao processo de complementaridade e consistência entre os bens de consumo, a que o autor chama de efeito Diderot, uma espécie de força de arranjo, conjunto e coerção que mantém unidos os bens de consumo. É o que ocorre, por exemplo, nas narrativas publicitárias (Rocha, 2006), em cuja estrutura pode-se perceber, rotineiramente, uma aproximação entre diferentes produtos e serviços, criando um conjunto coerente de significados e operando um diálogo dos bens de consumo entre si e deles com a vida social.

Sherry (1995, p. xv) afirmou que a recente fermentação na pesquisa sobre consumo e marketing seria resultante do novo interesse em questões culturais, "gerado pelo trabalho de pesquisadores treinados em Antropologia". De fato, a difusão da antropologia do consumo ocorre inicialmente pela inserção de antropólogos nas escolas de Administração - como é o caso de Russell Belk e de John Sherry Jr., entre outros -, que lideram o processo de difusão desse conhecimento no plano acadêmico internacional. Deve-se ainda, embora em menor escala, ao trabalho de antropólogos que se dedicaram à prática da pesquisa de marketing de cunho etnográfico, cujo expoente é, sem dúvida, Paco Underhill (1999). Na esteira desses desenvolvimentos, uma nova geração de pesquisadores de comportamento do consumidor, treinados nas escolas de Administração, passou a desenvolver estudos de inspiração etnográfica.

Levantamentos e comentários sobre estudos publicados no exterior já foram realizados e podem ser encontrados em Rocha et al. (1999), Barros (2002) e Rocha e Barros (2006), facilitando o acesso à produção internacional daqueles que desejam aprofundar seu conhecimento sobre o tema.

\section{O MÉTODO DA ANTROPOLOGIA}

A etnografia é o método de pesquisa criado pela Antropologia e que assumiu sua forma mais definitiva no início do século XX. Fazer etnografia significa, em termos bastante gerais, estudar as categorias que norteiam o pensamento e as práticas de grupos sociais concretos, 
historicamente datados, dotados de fronteiras culturais nítidas e características comuns de experiência. A primeira questão tipicamente etnográfica é, portanto, configurar um grupo como conjunto de atores sociais que compartilhe certa homogeneidade de pensamento, de ethos, de visão de mundo, de práticas e estilo de vida, que permita construir uma unidade sociológica significativa. Definir fronteiras capazes de estabelecer uma espécie de territorialidade simbólica é parte do cuidado etnográfico, e, nesse sentido, as etnografias são estudos concretos e pontuais, ouvindo a palavra dos informantes e captando a lógica interna de seus discursos. Implica conhecer os grupos a partir suas próprias percepções e entender como concebem e praticam suas experiências de vida.

A etnografia pode ser entendida como a "descrição densa" da experiência cultural (Geertz, 1978) e a investigação "por dentro" da realidade do grupo, sendo o conhecimento científico gerado a partir do ponto de vista nativo. Entre os recursos do método etnográfico há a perspectiva microscópica, a entrevista em profundidade, a observação participante, a investigação em detalhe, a captação da informação cultural em fonte primária, o relato das práticas sociais, a análise do discurso e a interpretação das representações de informantes. O esforço de compreender o outro nos seus próprios termos e a busca de relativização que isso implica são marcas próprias do projeto etnográfico.

De forma muito simplificada, pode-se dizer que existiram duas tradições marcantes na história da aplicação do método etnográfico. A primeira, voltada para a sociedade dita primitiva, tomou forma por meio do trabalho de alguns dos pais fundadores da Antropologia. Nesse sentido, a grande referência foi o trabalho de Malinowski com os nativos das ilhas Trobriand que deu origem, em 1922, ao clássico Os argonautas do Pacífico ocidental (Malinowski, 1976), modelando de forma definitiva o método ao consolidar entre os pesquisadores o princípio da longa convivência com o "outro" e a visão relativizadora que daí advém. Após a consolidação desse modelo nas sociedades tribais, o eixo de aplicação do método se amplifica, criando uma espécie de segunda tradição, na qual novos espaços começam a se firmar, incluindo, com a chamada Escola de Chicago, a etnografia no contexto urbano da sociedade industrial, em metrópoles cada vez mais complexas. Entre os antropólogos que estudaram comunidades urbanas, destaca-se Foote-Whyte (1981), que, no início dos anos de 1940, escreve o seu Street Corner Society sobre os Italian Americans de Boston, levando para esse contexto a idéia de observação participante, ao vivenciar o cotidiano como parte do grupo.
O estudo dos grupos urbanos e seus sistemas culturais abriram espaço para a utilização da etnografia na investigação de questões pontuais, mais visíveis em sociedades complexas e grandes cidades, tornando legítimo realizar etnografias sobre as formas pelas quais essas questões eram percebidas e como impactavam a vida dos grupos. Assim se tornou possível investigar significados de fenômenos como narrativa publicitária, consumo, moda, novelas de televisão, shoppings, entre outros, e as formas pelas quais eles estruturavam sistemas de classificação, definiam parâmetros do universo simbólico e construíam as identidades dos grupos. No caso do consumo, foram realizadas investigações etnográficas para a descrição de representações, de espaços e de práticas. Os pesquisadores, utilizando técnicas típicas da etnografia, buscavam captar informações sobre modelos, ideologias, significados coletivos ou percepções do grupo em relação às situações e hábitos de consumo compartilhados. Esses trabalhos mostram a viabilidade da investigação sobre as representações acionadas pela narrativa publicitária e o universo de práticas relacionados ao consumo, utilizando a etnografia.

O interesse pela investigação de pequenos grupos, a busca da identificação de visões de mundo, diversidade de percepções e de práticas de consumo, mostra a filiação desses temas à tradição de pesquisa etnográfica. Assim, de acordo com essa tradição, os estudos praticaram a observação participante em suas várias modalidades e conduziram entrevistas em profundidade com os informantes. O tempo de permanência junto ao grupo também seguia as prerrogativas do método, com longos períodos de campo, objetivando descrever "o ponto de vista nativo", a visão de mundo dos próprios atores sociais.

Rocha e Barros (2006) chamam a atenção para a redução do tempo de permanência em campo nos estudos urbanos de consumo e de possíveis perdas decorrentes dessa redução, uma vez que o contato prolongado seria fundamental ao entendimento dos significados subjacentes ao consumo.

\section{ESTUDOS DE INSPIRAÇÃO ETNOGRÁFICA NO BRASIL}

"Se é possível ser um pouquinho antropólogo, eu gostaria de fazer essa reivindicação." Com essas palavras, Sidney Levy (1995, p. ix) posiciona claramente o esforço de pesquisadores que não foram treinados na Antropologia, mas que desenvolveram estudos de consumo de inspiração etnográfica. No Brasil, esses esforços se 
iniciaram no Instituto Coppead de Administração da UFRJ a partir de 1990, com a criação da primeira linha de pesquisas no Brasil sobre Antropologia do Consumo por um dos autores deste pequeno ensaio de apresentação à "RAE-Clássicos", que realizou seu doutorado em Antropologia. Essa linha frutificou em inúmeros trabalhos que utilizaram métodos de inspiração etnográfica, ou quasi-etnography (Rocha e Barros, 2006), inicialmente apenas sob a condução do autor em questão, e posteriormente de outros professores da área de Marketing. Trabalhos dessa natureza também se desenvolveram mais recentemente, em escolas de negócios de outras instituições, como a UFRGS.

A Tabela 1 apresenta uma relação parcial de estudos de consumo de inspiração etnográfica realizados e publicados no Brasil, em sua maioria sob o formato de dissertações e teses, mas também como livros e trabalhos em anais dos dois principais congressos brasileiros de interesse para a área de Marketing: o Enanpad e o EMA.

Os estudos em questão, em sua maioria, trabalharam com grupos bem delimitados, buscando investigar aspectos específicos do consumo desses grupos, e como o consumo serve, entre outras coisas, para definir ou reconstruir identidades após transições, como no caso de mulheres separadas (Ferreira, 2002) e homossexuais (Pereira, Ayrosa e Ojima, 2005); para marcar o pertencimento a um grupo, como entre "patricinhas" (Walther, 2002) e "yuppies" (Silveira, 2002); para reafirmar a identidade étnica, como entre judeus do Rio de Janeiro (Blajberg, 2001) e entre membros de uma comunidade black do Rio de Janeiro (Lino, 2005); para mostrar status e hierarquia, como entre profissionais liberais negros (Soares, 2002) e pobres da favela da Rocinha (Mattoso, 2005a, 2005b; Mattoso e Rocha, 2005); para falar de relações de poder, como os consumidores insatisfeitos nos estudos de Chauvel (1999, 2000a, 2000b) e Giglio e Chauvel (2002). Alguns estudos também focalizaram o papel dos produtos em mediar as relações entre gerações (Kubota, 1999; Campos, Suarez e Casotti, 2006), ou em mediar a passagem da "casa" para a "rua" (Castilhos et al., 2006). A apropriação de espaços sociais representados pelo shopping center foi o objeto de estudo de Soares (2000a, 2000b), enquanto Castilhos e Cavedon (2003) preocuparam-se em estudar a interação entre os atores da troca em um mercado público. Outro enfoque adotado foi investigar de que forma os produtos, tendo já incorporado significados, como o status resultante de uma pseudopátina, podem transferi-los aos consumidores, que deles se apropriam para dizer algo a respeito de sua posição social (Almeida e Rocha, 2006).

\section{UMA AGENDA DE PESQUISA PARA 0 BRASIL}

A variedade dos estudos levantados sugere ricas possibilidades para o uso de métodos de inspiração etnográfica em marketing, embora apenas os primeiros passos tenham sido dados nessa direção.

Ao considerar as inúmeras alternativas que se abrem ao pesquisador em marketing, é conveniente iniciar pela clara demarcação dos estudos de inspiração etnográfica, para que não haja confusão quanto à inserção teórica a que aqui se faz referência. Em primeiro lugar, o consumo é um sistema de significação e a principal necessidade social que supre é a necessidade simbólica. Segundo, o consumo é como um código e por meio dele é traduzida boa parte das relações sociais e são elaboradas muitas das experiências de subjetividade. Terceiro, esse código, ao traduzir sentimentos e relações sociais, forma um sistema de classificação de coisas e pessoas, produtos e serviços, indivíduos e grupos. O consumo permite um exercício de classificação do mundo a partir de si mesmo, e, como é próprio dos códigos, pode ser sempre inclusivo: de um lado, inclusivo de novos produtos e serviços que a ele se agregam e são articulados aos demais; e de outro, inclusivo de identidades e relações sociais que são definidas, em larga medida, a partir dele. Finalmente, esse código possui uma instância que o viabiliza, ao comunicá-lo à sociedade. A mídia é a grande realizadora da dimensão pública desse código, permitindo a socialização para o consumo de forma semelhante, definindo publicamente produtos e serviços como necessidades, explicando-os como modos de uso, confeccionando desejos como classificações sociais. Por esse processo, marketing, mídia e publicidade são intérpretes da esfera da produção, socializando para o consumo ao disponibilizar um sistema classificatório que liga um produto a cada outro e todos juntos às experiências de vida dos consumidores.

Do ponto de vista metodológico, o estudo etnográfico é o método pelo qual é possível obter acesso às formas pelas quais os grupos sociais atribuem significados aos produtos e serviços, dando-lhes sentido diferenciado, incluindo-os ou excluindo-os de sua vida. Enfim; como experimentam o consumo e, por meio dele, traduzem afetos, desejos e relações sociais, construindo uma visão de mundo. A etnografia é um modo privilegiado de análise cultural e, por isso, é fundamental no entendimento dos sistemas simbólicos que articulam os objetos de consumo e a vida cotidiana dos atores sociais.

De que forma os pesquisadores de marketing podem, então, inserir-se no entendimento do consumo por meio de estudos de consumo de inspiração etnográfica? Se- 
Tabela 1 - Lista parcial de estudos de consumo de inspiração etnográfica no Brasil

\begin{tabular}{|c|c|c|c|}
\hline AUTOR(ES) & NATUREZA & TEMA & PRINCIPAIS QUESTÕES ABORDADAS \\
\hline Carvalho (1997) & Dissertação & $\begin{array}{l}\text { Consumo de objetos decorativos por casais de } \\
\text { classe média }\end{array}$ & Rituais, identidades, transições. \\
\hline Kubota (1999) & Dissertação & $\begin{array}{l}\text { Significados e práticas de consumo na tercei- } \\
\text { ra idade }\end{array}$ & $\begin{array}{l}\text { Dicotomia entre a "casa" e a "rua", diferen- } \\
\text { ças de gênero e geração, significado das } \\
\text { marcas. }\end{array}$ \\
\hline $\begin{array}{l}\text { Chauvel (1999, } \\
\text { 2000a, 2000b) }\end{array}$ & $\begin{array}{l}\text { Tese, anais, } \\
\text { livro }\end{array}$ & $\begin{array}{l}\text { Insatisfação dos consumidores de classe } \\
\text { média e baixa e estratégias para lidar com a } \\
\text { insatisfação }\end{array}$ & $\begin{array}{l}\text { Hierarquia, distinção, poder, significado das } \\
\text { marcas }\end{array}$ \\
\hline Ballvé (2000) & Dissertação & $\begin{array}{l}\text { Lógica de consumo de crianças da elite } \\
\text { carioca }\end{array}$ & $\begin{array}{l}\text { Construção do senso estético, aceitação de } \\
\text { rituais, comportamentos de consumo. }\end{array}$ \\
\hline Bellia (2000) & Dissertação & Lógica de consumo dos novos ricos cariocas & Senso estético, distinção. \\
\hline Ouchi (2000) & Dissertação & $\begin{array}{l}\text { Lógica de consumo de adolescentes de colégio } \\
\text { tradicional mineiro }\end{array}$ & $\begin{array}{l}\text { Identidade e pertencimento ao grupo, signifi- } \\
\text { cado das marcas, local versus global. }\end{array}$ \\
\hline $\begin{array}{l}\text { Soares } \\
(2000 a, 2000 b)\end{array}$ & $\begin{array}{l}\text { Dissertação, } \\
\text { anais }\end{array}$ & $\begin{array}{l}\text { Consumo em um shopping center da Zona Norte } \\
\text { do Rio de Janeiro }\end{array}$ & $\begin{array}{l}\text { Dicotomia entre "casa" e "rua”, apropriação } \\
\text { de espaços sociais, escolhas de consumo dos } \\
\text { atores sociais, busca da sociabilidade. }\end{array}$ \\
\hline Velho (2000) & Dissertação & $\begin{array}{l}\text { Impacto das telenovelas na difusão dos con- } \\
\text { ceitos de moda }\end{array}$ & Difusão da moda. \\
\hline Blajberg (2001) & Dissertação & $\begin{array}{l}\text { Padrões de consumo de um grupo de judeus } \\
\text { do Rio de Janeiro }\end{array}$ & $\begin{array}{l}\text { Tribalização e globalização; identidade étnica; } \\
\text { consumo, investimento e segurança. }\end{array}$ \\
\hline Ferreira (2002) & Dissertação & $\begin{array}{l}\text { Significado do consumo de mulheres separadas } \\
\text { e bem-sucedidas }\end{array}$ & $\begin{array}{l}\text { Identidade, individualidade, transições, } \\
\text { auto-estima. }\end{array}$ \\
\hline $\begin{array}{l}\text { Giglio e Chauvel } \\
\text { (2002) }\end{array}$ & Anais & $\begin{array}{l}\text { Estratégias utilizadas por consumidores insatis- } \\
\text { feitos de serviços de telefonia }\end{array}$ & Hierarquia, distinção, poder. \\
\hline Silveira (2002) & Dissertação & $\begin{array}{l}\text { Lógica de consumo de jovens profissionais do } \\
\text { mercado financeiro (yuppies) }\end{array}$ & $\begin{array}{l}\text { Individualidade, pertencimento a grupo, apa- } \\
\text { rência, estilo, senso estético. }\end{array}$ \\
\hline Soares (2002) & Dissertação & $\begin{array}{l}\text { Significado do consumo de profissionais liberais } \\
\text { negros bem-sucedidos }\end{array}$ & Identidade, distinção, hierarquia. \\
\hline Walther (2002) & Dissertação & $\begin{array}{l}\text { Lógica de consumo de adolescentes e jovens } \\
\text { muito ricas do Rio de Janeiro }\end{array}$ & $\begin{array}{l}\text { Auto-imagem, pertencimento a grupo, } \\
\text { consumismo. }\end{array}$ \\
\hline Martinez (2002) & Dissertação & Padrões de consumo de jovens católicos & Rejeição do consumismo, ideal de frugalidade. \\
\hline $\begin{array}{l}\text { Castilhos e } \\
\text { Cavedon (2003) }\end{array}$ & Anais & $\begin{array}{l}\text { Relações entre fornecedor, vendedor e cliente } \\
\text { em um mercado público de Porto Alegre }\end{array}$ & $\begin{array}{l}\text { Relacionamentos, reciprocidade, honra e } \\
\text { obrigação. }\end{array}$ \\
\hline Barros (2004) & Anais & $\begin{array}{l}\text { Esquema classificatório de restaurantes na per- } \\
\text { cepção dos consumidores }\end{array}$ & Distinção, sistemas de classificação. \\
\hline D’Angelo (2004) & Dissertação & Significados associados ao consumo do luxo & Distinção, hierarquia, status. \\
\hline $\begin{array}{l}\text { Castilhos et al. } \\
(2005)\end{array}$ & Anais & $\begin{array}{l}\text { Estrutura de consumo e significado dos pro- } \\
\text { dutos consumidos por famílias brasileiras e } \\
\text { francesas }\end{array}$ & $\begin{array}{l}\text { Cultura, hábitos de consumo, valorização da } \\
\text { "casa". }\end{array}$ \\
\hline
\end{tabular}




\begin{tabular}{|c|c|c|c|}
\hline $\begin{array}{l}\text { Fonseca e Mello } \\
(2005)\end{array}$ & Anais & Relação simbólica entre consumidor e marca & $\begin{array}{l}\text { Dicotomia entre "casa" e "rua", significado } \\
\text { das marcas. }\end{array}$ \\
\hline Lino (2005) & Dissertação & $\begin{array}{l}\text { Valores ligados ao consumo em uma comuni- } \\
\text { dade black do Rio de Janeiro }\end{array}$ & Identidade, pertencimento a grupo. \\
\hline Lopes (2005) & Dissertação & Relação entre beleza, maternidade e consumo & Gênero, transições. \\
\hline $\begin{array}{l}\text { Mattoso (2005a, } \\
\text { 2005b), Mattoso e } \\
\text { Rocha (2005) }\end{array}$ & $\begin{array}{l}\text { Tese, livro, } \\
\text { anais }\end{array}$ & $\begin{array}{l}\text { Significados simbólicos atribuídos a serviços } \\
\text { financeiros por consumidores pobres }\end{array}$ & $\begin{array}{l}\text { Identidade, distinção, hierarquia, ato de } \\
\text { presentear. }\end{array}$ \\
\hline $\begin{array}{l}\text { Pereira, Ayrosa e } \\
\text { Ojima (2005) }\end{array}$ & Anais & Uso do consumo por homossexuais & Identidade, transições. \\
\hline Strehlou (2005) & Anais & $\begin{array}{l}\text { Consumo de produtos de moda } \\
\text { falsificados }\end{array}$ & $\begin{array}{l}\text { Senso estético, estilo de vida, hierarquia } \\
\text { distinção. }\end{array}$ \\
\hline $\begin{array}{l}\text { Almeida e Rocha } \\
\text { (2006) }\end{array}$ & Anais & A presença da pátina nos objetos de consumo & Status, identidade da marca. \\
\hline Amui (2006) & Dissertação & Significados associados ao consumo de luxo & Distinção, hierarquia, status. \\
\hline Barros (2006) & Anais & $\begin{array}{l}\text { Significados do consumo para empregadas } \\
\text { domésticas }\end{array}$ & Hierarquia, mediação entre classes sociais. \\
\hline $\begin{array}{l}\text { Campos, Suarez e } \\
\text { Casotti (2006) }\end{array}$ & Anais & $\begin{array}{l}\text { Significados associados ao consumo de cosmé- } \\
\text { ticos por mães e filhas }\end{array}$ & $\begin{array}{l}\text { Relacionamento entre gerações, autonomia } \\
\text { identificação. }\end{array}$ \\
\hline $\begin{array}{l}\text { Castilhos et al. } \\
\text { (2006) }\end{array}$ & Anais & $\begin{array}{l}\text { Significado da posse de bens no ambiente de } \\
\text { trabalho }\end{array}$ & Identidade, mediação entre casa e trabalho. \\
\hline Rosário (2006) & Dissertação & $\begin{array}{l}\text { Comportamentos desviantes dos } \\
\text { consumidores }\end{array}$ & $\begin{array}{l}\text { Identidade, senso estético, rejeição de valores } \\
\text { tradicionais. }\end{array}$ \\
\hline Scaraboto (2006) & Dissertação & Comunidades virtuais como grupos de referência & Netnografia. \\
\hline Szuster (2006) & Dissertação & $\begin{array}{l}\text { Influência de ídolos de futebol no consumo de } \\
\text { adolescentes }\end{array}$ & $\begin{array}{l}\text { Construção da identidade, status, identidade } \\
\text { da marca. }\end{array}$ \\
\hline
\end{tabular}

gue-se um conjunto de pontos que parecem relevantes aos autores para garantir uma boa qualidade dos estudos realizados.

É importante dar continuidade ao estudo do consumo por meio da realização de etnografias de grupos de consumidores para que se possa obter um quadro preciso dos múltiplos códigos que ordenam as práticas de consumo. Seria interessante, ainda, pesquisar os significados que envolvem produtos e serviços pela experiência social que neles se inscreve nos meios de comunicação. Isso quer dizer estudar de que forma os produtos e serviços adquirem sentido ao se inserirem em redes de relações sociais construídas no mundo dentro da mídia. Os produtos e serviços assumem identidades em razão do trânsito que possuem em inúmeras cenas do cotidiano, pois são habitantes naturais, freqüentadores assíduos de dramas humanos projetados na mídia, e com eles adquirem significados e compartilham nossa humanidade.

Outra possibilidade seria estudar as múltiplas combinações que os produtos e serviços apresentam, percebendo como cada um se encaixa em sistemas de objetos, em cenários apropriados, em modelos classificatórios. Nessas redes simbólicas, os produtos e os serviços se prendem uns aos outros, tornam-se mutuamente dependentes, dialogam, ligam-se com outros tantos produtos e serviços, chamando-os para perto, colando estilos de vida, tipos de pessoas e variações de ambientes. Os produtos falam uns com os outros. Por exemplo, os bonecos das crianças formam sistemas e só existem em reunião com outros parceiros ou inimigos. E assim são os álbuns de figurinhas, cuja lógica é a da falta. Os produtos de moda, por sua vez, exigem acessórios e acompanhamentos, sem os quais sua presença pode apenas expor 
a exclusão social do portador. Outra vertente possível é a investigação dos significados que os produtos e serviços transmitem por meio de nomes, embalagens, cores e texturas; seu simbolismo e sua aparência; sua relação com práticas sociais, seu sentido classificatório, seu viés etnocêntrico, seu poder de exclusão e sua capacidade de transportar esperanças.

Algumas recomendações metodológicas também são cabíveis. Os grupos de consumo selecionados para estudo devem ser claramente delimitados, identificando-se, como já salientado, suas fronteiras culturais e experiências comuns. Deve-se frisar ainda a necessidade de dispor do que Levy (1981) chamou de "teoria de interpretação", requisito fundamental para um trabalho sério, sem o qual dificilmente se poderá passar do plano mais raso da descrição dos dados coletados ao entendimento mais elaborado dos significados associados ao consumo, da fala dos informantes ao desenvolvimento teórico. A convivência com o grupo estudado deve ser buscada da melhor forma possível, e o tempo de investigação deve encontrar-se nos limites razoáveis de uma etnografia urbana.

Para aqueles que ainda se iniciam nos estudos desta natureza sem dispor de treinamento específico, a réplica no Brasil de estudos realizados por autores consagrados e publicados em journals de prestígio pode ser um bom ponto de partida para o exercício do método. Saliente-se aqui que a réplica, pouco valorizada no Brasil, é fundamental para a expansão do conhecimento em qualquer área do saber. A vantagem de estudos iniciais baseados em réplica é, naturalmente, dispor de uma pauta de teoria e método contra a qual é possível avaliar os resultados obtidos.

Um aspecto fundamental é o desenvolvimento da parceria entre antropólogos e escolas de negócios, trazendo os primeiros aos programas de mestrado e doutorado, como alunos, e ao corpo docente das escolas. O primeiro movimento só poderá ser realizado se o processo de seleção das escolas de Administração brasileiras for capaz de abrir espaço para perfis distintos de alunos, já que os processos atuais têm forte viés favorável à formação quantitativa e positivista. O segundo movimento implica a compreensão de que a melhor forma de aprender é com aqueles que efetivamente dominam esse conhecimento, e que a multidisciplinaridade poderá ter papel relevante no desenvolvimento da qualidade do trabalho científico nas escolas de Administração. Assim, será por meio de um processo sistemático de troca e da tensão por ela gerada que a produção intelectual de excelência e pesquisa de ponta nessa área encontrarão o espaço propício para seu desenvolvimento.

\section{REFERÊNCIAS}

ALMEIDA, V.; ROCHA, A. O efeito pátina nas marcas: uma reflexão sobre a inscrição de signos conotativos da passagem do tempo nos objetos de consumo. In: ENCONTRO DE MARKETING DA Anpad, 2., 2006. Anais. Rio de Janeiro: ANPAD, 2006

AMUI, I. C. O comportamento do consumidor de cosméticos de luxo. Dissertação de Mestrado. Rio de Janeiro: Coppead/UFRJ, 2006.

BALLVÉ, F. A criança e a experiência do consumo. Dissertação de Mestrado. Rio de Janeiro: Coppead/UFRJ, 2000.

BARROS, C. Marketing e etnografia: um levantamento em journals nos anos 80 e 90. In: ENCONTRO NACIONAL DE PROGRAMAS DE PÓSGRADUAÇÃO E PESQUISA EM ADMINISTRAÇÃO, 26., 2002, Salvador Anais. Salvador: ANPAD, 2002.

BARROS, C. Classificação de restaurantes a partir da visão do consumidor um estudo etnográfico. In: ENCONTRO NACIONAL DE PROGRAMAS DE PÓS-GRADUAÇ̃̃O E PESQUISA EM ADMINISTRAÇÃO, 28., 2004, Curitiba. Anais. Curitiba: ANPAD, 2004

BARROS, C. Consumo, hierarquia e mediação: um estudo antropológico no universo das empregadas domésticas. In: ENCONTRO NACIONAL DE PROGRAMAS DE PÓS-GRADUAÇÃO E PESQUISA EM ADMINISTRACÃO, 30., 2006, Salvador. Anais. Salvador: ANPAD, 2006.

BELLIA, L. O consumo dos moradores da Barra da Tijuca. Dissertação de Mestrado. Rio de Janeiro: Coppead/UFRJ, 2000

BLAJBERG, C. Em busca de uma identidade. Dissertação de Mestrado. Rio de Janeiro: Coppead/UFRJ, 2001

BOYD, H. W. Marketing Management: An Analytical Problem Solving Approach to Marketing. New York: Harcourt Brace Jovanovich, 1972

CAMPOS, R. D.; SUAREZ, M.; CASOTTI, L. M. Me explica o que é ser feminina? Um estudo sobre a influência entre gerações no consumo de cosméticos. In: ENCONTRO DE MARKETING DA ASSOCIAÇÃO NACIONAL DOS PROGRAMAS DE PÓS-GRADUACCÃO E PESQUISAS EM ADMINISTRAÇÃO, 2., 2006, Rio de Janeiro. Anais. Rio de Janeiro: ANPAD, 2006.

CARVAlHo, C. A. Simbologia de objetos decorativos. Dissertação de Mestrado. Rio de Janeiro: Coppead/UFRJ, 1997.

CASTILHOS, R. B.; CAVEDON, N. R. Fornecedor, mercadeiro e cliente: um ensaio sobre as trocas no Mercado Público Central de Porto Alegre. In: ENCONTRO NACIONAL DE PROGRAMAS DE PÓS-GRADUAÇÃO E PESQUISA EM ADMINISTRAÇÃO, 37., 2003, Atibaia. Anais. Atibaia: ANPAD, 2003 
CASTILHOS, R. B.; ROSSI, C. A. V.; CAVEDON, N. R. Cultura e consumo de famílias no Brasil e na França. In: ENCONTRO NACIONAL DE PROGRAMAS DE PÓS-GRADUAÇÃO E PESQUISA EM ADMINISTRAÇÃO, 29., 2005, Brasília. Anais. Brasília: ANPAD, 2005.

CASTILHOS, R. B.; PETERSEN-WAGNER, R.; SILVEIRA, C. S.; KEISERMAN, B.; MERINO, M. H.; ROSSI, C. A. V. Self estendido e posse no local de trabalho: uma réplica no contexto brasileiro. In: ENCONTRO DE MARKETING DA ASSOCIAČ̃̃O NACIONAL DOS PROGRAMAS DE PÓS-GRADUAÇÃO E PESQUISAS EM ADMINISTRAÇÃO, 2., 2006, Rio de Janeiro. Anais. Rio de Janeiro: ANPAD, 2006.

CHAUVEL, M. A. Representações e lógicas de ação do consumidor insatisfeito. Tese de Doutorado. Rio de Janeiro: Coppead/UFRJ, 1999.

CHAUVEL, M. A. Insatisfação e queixa às empresas: investigando os relatos dos consumidores. In: ENCONTRO DA ASSOCIAÇÃO NACIONAL DOS PROGRAMAS DE PÓS-GRADUAÇÃO E PESQUISAS EM ADMINISTRAÇÃO, 24., 2000a, Rio de Janeiro. Anais. Rio de Janeiro: ANPAD, 2000a.

CHAUVEL, M. A. Consumidores insatisfeitos: uma oportunidade para as empresas. Rio de Janeiro: Mauad, 2000b.

D'ANGELO, A. C. Valores e significados do consumo de produtos de luxo. Dissertação de Mestrado. Porto Alegre: PPGA/UFRGS, 2004.

DOUGLAS, M.; ISHERWOOD, B. The world of goods: towards an anthropology of consumption. New York: Norton, 1979.

FERREIRA, M. L. Reconstruindo a identidade. Dissertação de Mestrado. Rio de Janeiro: Coppead/UFRJ, 2002.

FONSÊCA, F. R. B.; MELLO, S. B. Clarificando a identidade do fenômeno relacional marca-consumidor: uma visão proveniente da antropologia social ou eu vou, eu vou, para o McDonald's, agora eu vou... In: ENCONTRO DE ASSOCIAÇÃO NACIONAL DOS PROGRAMAS DE PÓS-GRADUAÇÃO E PESQUISAS EM ADMINISTRAÇÃO, 29., 2005, Brasília. Anais. Brasília: ANPAD, 2005.

FOOTE-WHYTE, W. Street corner society. Chicago: University of Chicago Press, 1981.

GAINER, B. Ritual and relationships: interpersonal influences on shared consumption. Journal of Business Research, v. 32, n. 3, p. 253-260, 1995.

GAINER, B.; FISCHER, E. To buy or not to buy - that is not the question: female ritual in home shopping parties. In: HOLMAN, R.; SOLOMON, M. (Orgs.). Advances in Consumer Research, Vol. 18. Provo, Utah: Association for Consumer Research, 1991. p. 597-602.

GEERTZ, C. A interpretação das culturas. Rio de Janeiro: Zahar, 1978.

GIGLIO, E.A.M.; CHAUVEL, M.A. Reclamação e cultura brasileira: um estudo baseado na análise de cartas de consumidores insatisfeitos à imprensa. In: ENCONTRO DE ASSOCIAČÃO NACIONAL DOS PROGRAMAS DE PÓS-GRADUAÇÃO E PESQUISAS EM ADMINISTRAÇÃO, 26., 2002, Salvador. Anais. Salvador: ANPAD, 2002
HALL, E. T. The Hidden Dimension. New York: Doubleday, 1966.

HALL, E.T. The Dance of Life. New York: Anchor/Doubleday, 1984.

HOFSTEDE, G. Culture's Consequences: International Differences in WorkRelated Values. Abridged edition. Newbury Park, CA: Sage, 1984.

HOFSTEDE, G. Cultures and Organizations: Software of the Mind. London: McGraw-Hill, 1991.

KUBOTA, L. C. Consumo e ciclo de vida. Dissertação de Mestrado. Rio de Janeiro: Coppead/UFRJ, 1999.

LEVY, S. Interpreting consumer mythology: a structural approach to consumer behavior. Journal of Marketing, v. 45, n. 3, p. 49-61, 1981.

LEVY, S. Foreword: Does marketing need anthropology? In: SHERRY, J.F, JR. Contemporary Marketing and Consumer Behavior: An Anthropological Sourcebook. Thousand Oaks, CA: Sage, 1995, p. 9-14.

LINO, B. B. Valores de ligação no comportamento de consumo: um estudo exploratório em uma comunidade black do Rio de Janeiro. Dissertação de Mestrado. Rio de Janeiro: Coppead/UFRJ, 2005.

LOPES, M. O conceito de beleza e maternidade: um estudo exploratório sobre o comportamento feminino. Dissertação de Mestrado. Rio de Janeiro: Coppead/UFRJ, 2005.

MALINOWSKI, B. Argonautas do Pacífico ocidental. São Paulo: Abril Cultural, 1984.

MARTINEZ, C. Os paradoxos do consumo. Dissertação de Mestrado. Rio de Janeiro: Coppead/UFRJ, 2002.

MATTOSO, C. Identidade, inserção social e acesso a serviços financeiros: um estudo na favela da Rocinha. Tese de Doutorado. Rio de Janeiro: Coppead/UFRJ, 2005a.

MATTOSO, C. Me empresta seu nome? Um estudo sobre os consumidores pobres e seus problemas financeiros. Rio de Janeiro: Mauad, 2005b.

MATTOSO, C.; ROCHA, A. Significados associados às estratégias para solução de problemas financeiros dos consumidores pobres. In: ENCONTRO DE ASSOCIAČ̃̃O NACIONAL DOS PROGRAMAS DE PÓS-GRADUAÇÃO E PESQUISAS EM ADMINISTRAÇÃO, 29., 2005, Brasília. Anais Brasília: ANPAD, 2005

MCCRACKEN, G. Culture and consumption: a theoretical account of the structure and movement of the cultural meaning of consumer goods. Journal of Consumer Research, v. 13, n. 1, p. 71-84, 1986.

MCCRACKEN, G. Cultura e consumo. Rio de Janeiro: Mauad, 2003. 
OUCHI, C. O global e o local na construção da identidade. Dissertação de Mestrado. Rio de Janeiro: Coppead/UFRJ, 2000.

PEREIRA, B. N. P.; AYROSA, E. A. T.; OJIMA, S. Consumo entre gays: compreendendo a construção da identidade homossexual através do consumo. In: ENCONTRO DE ASSOCIAÇÃO NACIONAL DOS PROGRAMAS DE PÓS-GRADUAÇÃO E PESQUISAS EM ADMINISTRAÇÃO, 29., 2005, Brasília. Anais. Brasília: ANPAD, 2005.

ROCHA, E. ET AL. Cultura e consumo: um roteiro de estudos e pesquisas. In: ENCONTRO DE ASSOCIAÇÃO NACIONAL DOS PROGRAMAS DE PÓS-GRADUAÇÃO E PESQUISAS EM ADMINISTRAÇÃO, 23., 1999, Foz do Iguaçu. Anais. Foz do Iguaçu: ANPAD, 1999.

ROCHA, E.; BARROS, C. Dimensões culturais do marketing: teoria antropológica, etnografia e comportamento do consumidor. Revista de Administração de Empresas, v. 46, n. 4, p. 36-47, 2006.

ROCHA, E. Representações do consumo: estudos sobre a narrativa publicitária. Rio de Janeiro: Mauad, 2006.

ROOK, D. W. The ritual dimension of consumer behavior. Journal of Consumer Research, v. 12, n. 3, p. 251-264, 1985.

ROSÁRIO, F. Padrões estéticos e comportamento desviante: um estudo exploratório com mulheres que não pintam o cabelo. Dissertação de Mestrado. Rio de Janeiro: Coppead/UFRJ, 2006.

SCARABOTO, D. Comunidades virtuais como grupos de referência nos processos decisórios do consumidor. Dissertação de Mestrado. Porto Alegre: PPGA/UFRGS, 2006.

SCHOUTEN, J. W. Selves in transition: symbolic consumption in personal rites of passage and identity reconstruction. Journal of Consumer Research, v. 17, n. 4 , p. $412-425,1991$.

SHERRY JR., J. F. Anthropology of marketing and consumption: retrospect and prospect. In: SHERRY JR., J. F. Contemporary Marketing and Consumer Behavior: An Anthropological Sourcebook. Thousand Oaks, CA: Sage, 1995.
SILVEIRA, T. Luxo, moda e marca. Dissertação de Mestrado. Rio de Janeiro: Coppead/UFRJ, 2002.

SOARES, J. A singularidade invisivivel. Dissertação de Mestrado. Rio de Janeiro: Coppead/UFRJ, 2002.

SOARES, L. A. Entre a casa e a rua: cultura, espaço e consumo em shopping centers. Dissertação de Mestrado. Rio de Janeiro: Coppead/UFRJ, 2000.

SOARES, L. A. Entre a "casa" e a "rua": revisitando o espaço shopping center no Brasil. In: ENCONTRO DE ASSOCIAČ̃̃O NACIONAL DOS PROGRAMAS DE PÓS-GRADUAČ̃̃O E PESQUISAS EM ADMINISTRAČ̃̃O, 24. 2000b, Florianópolis. Anais. Florianópolis: ANPAD, 2000b.

STANTON, W. J. Fundamentals of Marketing. New York: McGraw-Hill, 1970.

STREHLOU, S. A teoria do gosto de Bourdieu aplicada ao consumo de marcas de luxo falsificadas. In: ENCONTRO DE ASSOCIAÇÃO NACIONAL DOS PROGRAMAS DE PÓS-GRADUAÇÃO E PESQUISAS EM ADMINISTRAČ̃̃O, 29., 2005, Brasília. Anais. Brasília: ANPAD, 2005.

SZUSTER, F. A influência de ídolos de futebol no consumo: um estudo exploratório com adolescentes. Dissertação de Mestrado. Rio de Janeiro: Coppead/UFRJ, 2006.

UNDERHILL, P. Vamos às compras! A ciência do consumo. Rio de Janeiro: Campus, 1999

VELHO, B. A moda brasileira e a telenovela: um estudo exploratório. Dissertação de Mestrado. Rio de Janeiro: Coppead/UFRJ, 2000.

WALTHER, L. Imagem, luxo e dilema. Dissertação de Mestrado. Rio de Janeiro: Coppead/UFRJ, 2002

\section{Artigo convidado. Aprovado em 29.12.2006.}

